\title{
A MULHER BRASILEIRA: DA FOTOGRAFIA COLONIAL À FOTOGRAFIA PORTUGUESA CONTEMPORÂNEA
}

\author{
Lorena Travassos
}

\begin{abstract}
Resumo
O presente trabalho se propõe a realizar uma análise inicial sobre a formação da imagem da mulher brasileira considerando o discurso historicamente construído e reforçado na fotografia colonial. Tal visualidade resiste através dos tempos, consistindo em uma forma de colonialismo contemporâneo por caracterizar-se como uma ação reducionista das identidades, em dissimulação de uma ideologia globalizada. A possibilidade de criação de paradoxo a esses discursos é analisada por meio da reflexão dos trabalhos de André Cepeda e Miguel Valle de Figueiredo, fotógrafos portugueses que possuem trabalhos fotográficos acerca da mulher brasileira. Nestas fotografias, a construção da mulher brasileira revelou discursos apoiados em percepções e experiências, como também em atribuições de valores generalizantes. Deste modo, concluiu-se que o entendimento sobre a imagem da mulher brasileira, conforme olhar desses fotógrafos, se mostra revestido de novos processos colonizadores em que à imagem da brasileira associa-se um corpo disponível e sensual, impreg nado pela compreensão de um corpo colonial que ainda persiste no imaginário contemporâneo.
\end{abstract}

Palavras-chave

Visualidade; fotografia; colonialismo; imagem da mulher brasileira

\begin{abstract}
This study aims to carry out an initial analysis of how the Brazilian woman image is shaped by a discourse that is historically constructed and reinforced by colonial photography. This visuality has endured through the ages and represents a form of contemporary colonialism, as it is characterized by an identity reductionism disguised as a global ideology. The possibility of paradox prevalence in these speeches is analyzed through a critical view of the work of André Cepeda and Miguel Valle de Figueiredo, Portuguese photographers who has produced photography artwork about the Brazilian woman. In these images, the construction of a visual concept of Brazilian women revealed underlying statements supported by their perceptions and experiences, as well as in generalized beliefs. Thus, it was concluded that the understanding of the image of Brazilian women as portrayed by those photographers shows itself covered of brand new colonizing processes in which the Brazilian woman's image is linked with a sense of an available and sensual body, imbued with the concept of a colonial body that still persists in contemporary imagery.
\end{abstract}

KEYWORDS

Visuality; photography; colonialism; brazilian woman image 


\section{INTRODUÇÃo}

O surgimento da fotografia no século XIX trouxe consigo a ideia de uma veracidade indiscutível dos fatos representados. O seu status de verdade permitiu o entendimento de que ao registar o mundo "real" ela o faz da forma que "realmente" se apresenta. Isto concede à lembrança o entendimento de que os fatos foram apresentados como realmente se parecem. Por isso, a memória e fotografia se confundem, uma parece não funcionar sem a outra.

Contudo, tanto a fotografia como a memória não são suficientes para conferir credibilidade absoluta a um determinado fato. Como a memória, a fotografia seleciona partes do acontecimento para enganar, manipular ou realçar ideologias ao "fazer parecer". Apesar disso, a fotografia ainda constitui-se como um dos melhores processos de rememoração (Le Goff, 2003).

A fotografia, ao mesmo tempo que permite a rememoração do que se é visto, permite também um olhar estigmatizado de pessoas e lugares que obedece à intenção de quem fotografa. Mesmo quando utilizada como uma técnica documental, permite também a criação e profusão de sentido. É neste processo que transparece a definição identitária do Outro. Por isso, no período colonial, a fotografia foi responsável por imprimir noções racistas, que representava, muitas vezes, um quadro falso de acontecimentos, sujeitos e circunstâncias históricas (Roberts, 1988).

Sabe-se que as relações de género seguiram de mãos dadas com a fotografia ao conferir um papel inferior às mulheres não-europeias, com a exibição de um corpo nu e disponível ao colonizador. Esse "olhar masculino" marcou todo o período colonial, nomeadamente quando passou a registar civilizações e indivíduos que se distanciavam do discurso europeu como seres inferiores, selvagens e incapazes. Tal uso da fotografia criou o conceito de fotografia colonial (Edwards, 2008), ou seja, aquela que regista o discurso do colonizador que, por sua vez, se coloca em um lugar de superioridade em relação a quem está sendo captado por sua câmara, desvelando o mundo "desconhecido e bárbaro".

Deste modo, a fotografia tornou-se um meio reprodutor de assimetria cultural e de género desde sua invenção. Suas imagens povoaram o imaginário de muitos europeus que passaram a conhecer o mundo através das imagens dos fotógrafos viajantes. Devido a essa função de memória, ideias colonialistas são ainda repetidas nas imagens contemporâneas vistas, principalmente, na reprodução de estereótipos de caráter patriarcal e imperialista, ideias combatidas pelo feminismo e pós-colonialismo.

A presença quase nula da mulher na vida social no período colonial refletiu-se em uma representação do seu corpo conforme o olhar masculino. Havia uma vigilância constante dos modos e da aparência, portanto, a imagem da mulher buscava refletir seus "bons costumes". Essa ideia de recato não foi imposta apenas pelos homens, foi também incutida na mente das mulheres ao ponto de se desenvolver uma autovigilância de si, com a educação de um autocontrole desde a infância (Berger, 1972).

Por isso, é preciso compreender que o olhar masculino é mais do que "olhar do homem", ele representa um lugar. Para Laura Mulvey (1989), a mulher também pode ter um olhar "masculino" na posição de espectador ao observar outra mulher na imagem, 
momento em que revive o aspecto perdido de sua sexualidade. A mulher representada de forma objetificada no cinema, parece proporcionar à mulher espectadora o lugar masculino do olhar e do prazer. Assim, o corpo-objeto feminino dá abertura a uma "estética da curiosidade" (Mulvey, 1996) que contrapõe a escopofilia machista.

Toma-se o conjunto das imagens das mulheres "não como ilustração da história, mas como uma história em si mesma" (Higonnet, 1992, p. 140). Nessas imagens, a representação deve ser vista como uma "função normativa de uma linguagem que revelaria ou distorceria o que é tido como verdadeiro sobre a categoria das mulheres" (Butler, 1997, p. 18). Ao ter a consciência dessa função normativa da imagem, procura-se escová-la a contrapelo para fazer surgir as marcas e contaminações de ideias antigas que se instalam como nódoas na imagem da mulher brasileira.

A presente reflexão dedica-se a uma breve análise da criação de uma visualidade que representa a mulher brasileira na fotografia portuguesa. Para isto, foi proposto um olhar teórico sobre a imagem do corpo da mulher, além de um olhar histórico sobre as imagens da mulher brasileira em fotografias coloniais e nos jornais portugueses. Com base nisto, foram analisados os trabalhos de dois fotógrafos portugueses contemporâneos: Miguel Valle de Figueiredo e André Cepeda. Ambos estiveram no Brasil e retrataram a mulher brasileira em seus trabalhos.

\section{A IMAGEM DO CORPO DA MULHER: OBJETIFICAÇÃO E FETICHISMO}

O corpo, direta ou indiretamente, permite visualizar uma grande quantidade de questões que são extremamente significantes: noções de raça, conceito de beleza, sexualidade, crenças e noções de moralidade, além da distinção entre "selvagem" e civilizado. Para William Ewing (1996), as fotografias que têm como objeto o corpo do ser humano são políticas, pois são utilizadas para controlar opiniões ou influenciar ações. Esse tipo de imagem alcança maior impacto no imaginário social que as imagens televisivas. São elas que ficam marcadas na memória como identidade do Outro.

Quando se apresenta de forma erótica, o corpo depende da classificação de tipos sociais. As lavadeiras, por trabalharem em locais abertos foram consideradas mulheres de sexualidade perdida (Henning, 1996). Mesmo hoje, a fotografia erótica trabalha com a classificação de seus temas em tipos reconhecíveis. Por seu lado, a publicidade tem representado o corpo da mulher baseado em graus de nudez explícita ou atividade sexual, de forma a erotizar o corpo feminino e transformá-lo em objeto para o olhar masculino. Para Michele Henning (1996), isto é o que se chama de objetificação do corpo feminino.

Este conceito tem especial relevância quando se trata da fotografia, pois ela também objetifica, pela segunda vez, ao tornar pessoas em objetos da visão. Para Solomon-Godeau (1991, p. 237) "a mais insidiosa e instrumental forma de domínio e subjugação e objetificação é produzida pelas imagens mais comuns da mulher (o que acontece de uma forma muito mais eficaz) do que as imagens policiais ou obscenas". Para ela, a história da fotografia se confunde com a história social da mulher, dado que a fotografia tem um cariz voyeur ou fetichista da mulher. 
A palavra fetiche vem do latim facere, que significa fazer ou construir. Esta palavra foi utilizada pela primeira vez no século XV por mercadores e colonos portugueses com referência à veneração africana por amuletos e ídolos religiosos, ou seja, teve início com referência ao feitiço. Fetichismo seria, então, o ato de adorar um fetiche (Hirschfeld, 1982); de incorporar uma propriedade mágica ao objeto de fetiche. Isso inclui a iconolatria cristã que atribui poder aos santos que também podem manifestar-se milagrosamente no plano físico.

Na psicanálise, um objeto torna-se um fetiche quando é foco de um desejo sexual, normalmente associado ao sexo feminino. Isto porque o fetichista idealiza objetos associados à mulher, como sapatos e batom. Para Freud, de acordo com o que introduz nos Três ensaios sobre a teoria da sexualidade, redigidos em 1905, trata-se de uma aberração, quase uma patologia, pois substitui o ato sexual "normal". Fetiche é "um substituto para o pénis da mulher (da mãe) em que o menininho outrora acreditou e - por razões que nos são familiares - não deseja abandonar (...), pois se uma mulher foi castrada, então a posse de seu próprio pénis estaria em perigo" (Freud, 1974, p. 180). Segundo o pai da psicanálise, a escolha do objeto de fetiche não depende da semelhança com o pénis, mas sim do momento de fratura, de trauma, ocorrido na primeira infância, quando o menino percebe que a mãe não possui um pénis. É neste instante que o primeiro objeto que é visto torna-se o seu fetiche, derivado da própria angústia de castração.

A importância desta teoria para o estudo da fotografia é que ela serve como ferramenta para explorar as formas como as imagens visuais podem objetificar e fragmentar o corpo da mulher, o que acontece de forma totalmente diferente do corpo masculino. No entanto, há um problema: o fetichismo é baseado na castração masculina e, por isso, só o qualifica como masculino e ignora que possa vir a surgir em outros géneros. O corpo feminino se mostra então como aquele que hospeda o fetiche para o masculino.

Neste sentido, Christian Metz (1985) convoca a obra de Freud ao falar que a fotografia e o fetiche carregam consigo a mesma contradição e singularidade. Enquanto a fotografia fixa o momento e nos permite carregar connosco a imagem, o fetichismo congela um momento e o fixa na memória do fetichista. $O$ fetiche sugere que a fotografia convoca os mortos e ao mesmo tempo mantém sua memória no passado. A simultaneidade temporal e a dimensão material permite que o objeto fotográfico seja objeto de fetiche.

Laura Mulvey, crítica de filmes, também utilizou a psicanálise para uma profunda crítica da imagem, sobretudo a do cinema. Neste contexto, a teoria psicanalítica foi utilizada para desvendar como "o inconsciente da sociedade patriarcal tem estruturado a forma do cinema" (1975, p. 6). Em Visual Pleasure and Narrative Cinema (1975), ela fala da existência de um ponto de vista masculino que se mostra nas artes visuais e literatura. O "olhar masculino" (male gaze) pode ser observado com o uso constante do close da câmara para mostrar detalhes do corpo, pois fragmenta a mulher na mente do espectador. Com a utilização da teoria do fetichismo, a autora fala da objetificação da mulher a partir do momento em que ela é representada como espetáculo. Neste sentido, o homem (heterossexual) é o olhar e a imagem é a mulher. Estas posições são envolvidas 
pelo complexo de castração, momento em que a mulher representa a falta, a diferença sexual. Para escapar da ansiedade da castração, o homem situa a mulher em um posição desvalorizada como punição (voyeurismo) ou substitui a figura feminina por um fetiche (objeto de desejo).

No entanto, mais à frente, a autora pensou no fetichismo não como pertencente a um olhar sexual dominante, mas sim como uma forma culturalmente dominante de ver o mundo. Com o artigo "Afterthoughts on 'Visual Pleasure and Narrative Cinema' inspired by King Vidor's Duel in the Sun (1946)", Mulvey (1989) atualizou seu pensamento com a inserção de dois outros elementos: a mulher como espectador e a personagem feminina protagonista. A mulher ao ser espectadora reflete o "olhar masculino" que nada mais é que uma posição no mundo, ou seja, retrata uma masculinização da posição do espectador. A mulher assume um lugar masculino para reviver o aspecto perdido de sua sexualidade, a castração, com o olhar e o prazer e, neste sentido, deixa de ser passiva, para exibir a masculinidade como ponto de vista.

Para buscar ver além de uma oposição binária, masculino e feminino, Mulvey desenvolveu mais profundamente esta teoria em Fetishism and Curiosity (1996). Para a cineasta, a mulher como espectadora exerce função semelhante à de Pandora ao abrir a caixa. A curiosidade exerce um fascínio pela imagem e, por isso, mostra-se como fonte de saber. Neste caminho, ela desenvolve a ideia de uma "estética da curiosidade" para contrapor o olhar masculino que fetichiza a imagem ao olhar curioso de Pandora para a caixa. Ela transforma o mito que tem o significado misógino, pois mostra a mulher como culpada por todo o mal do mundo, em uma curiosidade que tem dimensões políticas ao interpretar imagens. "Enquanto curiosidade é um desejo compulsivo de ver e saber, de investigar algo secreto, fetichismo é sustentado por uma recusa de ver, por uma recusa em aceitar a diferença que o corpo feminino representa para o masculino" (Mulvey, 1996, p. 64).

Com esta proposta de uma epistemofilia como resistência à escopofilia machista, Mulvey (1996) sugere ainda e sempre a necessidade de modulação do seu próprio argumento, para que se permita uma relação mais dialógica entre fetichismo e curiosidade. Refletir sobre a imagem da mulher, portanto, é saber que, além de ela ser composta por uma teia complexa de significados adquiridos ao longo do tempo, a sua representação possui significados políticos e sua recepção situa-se para além do "olhar masculino" ou mesmo de um olhar bipartido em masculino e feminino.

\section{A FOTOGRAFIA NA CONSTRUÇÃo IDENTITÁRIA Do “OUTRO”}

Segundo Juan Naranjo, na introdução do livro Fotografia, antropologia y colonialismo (2006), os avanços da tecnologia de impressão de imagens, iniciados a partir do início do século XIX, permitiu a expansão da circulação das imagens impressas de uma forma superior aos séculos anteriores. A proliferação da utilização de dispositivos ópticos, tanto no sector público como privado, modificaram os hábitos sociais, introduzindo mudanças nas formas de recepção e distribuição da informação. Apenas 
na segunda metade do século XIX, foi criada uma "indústria visual" com incrível densidade iconográfica.

A fotografia passou então a desempenhar um papel fundamental na transformação cultural, especialmente a partir do momento em que a imagem foi posta junto à palavra impressa, apesar da fotografia apagar as fronteiras entre a realidade e sua representação. Foi justo a mimese ilusória, que a fotografia forneceria entre o objeto e sua imagem, além de sua capacidade de multiplicação, que tornou a fotografia uma das médias com maior penetração social. Os avanços nos processos fotográficos possibilitaram o surgimento de sua indústria, abrindo espaço para a comercialização em larga escala de fotografias a preços econômicos, a exemplo das cartes de visite. Ao adquirir longo alcance, iniciou-se um amplo processo de democratização da informação visual, posto que a aquisição da fotografia substituía a experiência direta pela observação virtual das pessoas e paisagens de locais distantes.

Devido à expansão da indústria fotográfica e ao aumento do consumo de fotografias, muitas empresas ampliaram sua oferta e, como se necessário fosse, inventariaram o mundo enviando fotógrafos a todos os lados do planeta para documentar o que viram. Ao mesmo tempo, em sítios distantes foram abertos numerosos estúdios fotográficos que cumpriam dupla função: a de fotografar a burguesia local, os colonos, missionários, marinheiros e a de fotografar tipos de humanos que chegavam nas principais cidades e portos. O objetivo era a aquisição dessas imagens pelos viajantes e turistas.

O início da grande circulação de fotografias tornou "familiar" a imagem do "outro", tanto para a classe científica como para a burguesia da época. Apesar de alguns pesquisadores, como os antropólogos, utilizarem as fotografias coloniais para análise em detrimento da pesquisa de campo, outros estudiosos contestavam a veracidade dessas imagens, a exemplo das cartes de visite, por terem, sobretudo, um potencial comercial. Os estudiosos contrários asseveravam que essas imagens possuíam um padrão preestabelecido para que as informações alcançassem melhor compreensão e para facilitar a comparação e, por isso, elas raramente iriam servir como base de estudos científicos sérios.

As fotografias realizadas no período colonial europeu apresentavam temas eram inventados em modos genéricos e não havia esforço para identificar o fotógrafo e o acontecimento com profundidade. Por isso, é preciso utilizar a fotografia da época colonial de forma crítica', desafio muito importante para quem utiliza a análise fotográfica em pesquisas científicas até hoje.

A contaminação do comportamento europeu nos modos de vida das tribos retratadas, que muitas vezes levou ao extermínio total dessas culturas, foi outro fator responsável por tornar as fotografias comerciais coloniais inutilizáveis em pesquisas antropológicas, fator que foi resultado do rápido processo de expansão colonial no século XIX. Grande parte desse tipo de fotografia reproduzia todo o tipo de fantasias relacionadas

\footnotetext{
' Ver sobre este assunto o projeto Photo Clec (Photographs, Colonial Legacy and Museums in Contemporary European Culture), disponível em: http://photoclec.dmu.ac.uk/
} 
com o orientalismo ${ }^{2}$ e outros exotismos. Desse modo, tais fotografias foram utilizadas para criar identidades estereotipadas que satisfaziam aos consumidores românticos europeus.

Há também fortes relações de gênero que permeiam a fotografia da época colonial, com a atribuição de um papel inferior às mulheres, especialmente aquelas não-europeias. Fotografias de mulheres seminuas ou mesmo nuas, independente da raça e do país colonizado, são sempre presentes na visualidade colonial, o que pode ser explicado, segundo Filipa Vicente (2014, p. 22), como "resultado de uma dominação em relação ao visível - em relação àquilo que pode se tornar visível - assim como da hegemonia masculina no espaço colonial". Entre os problemas éticos que estas imagens colocam, Vicente (2014, p. 26), ao se deparar com as obras escultóricas de Vasco Araújo, uma das quais intitulada Botânica3 (Figura 1), aponta: "mas se ela fosse a sua mulher, esposa, branca, numa aldeia portuguesa e não em África, o soldado português deixar-se-ia assim fotografar por alguém?"

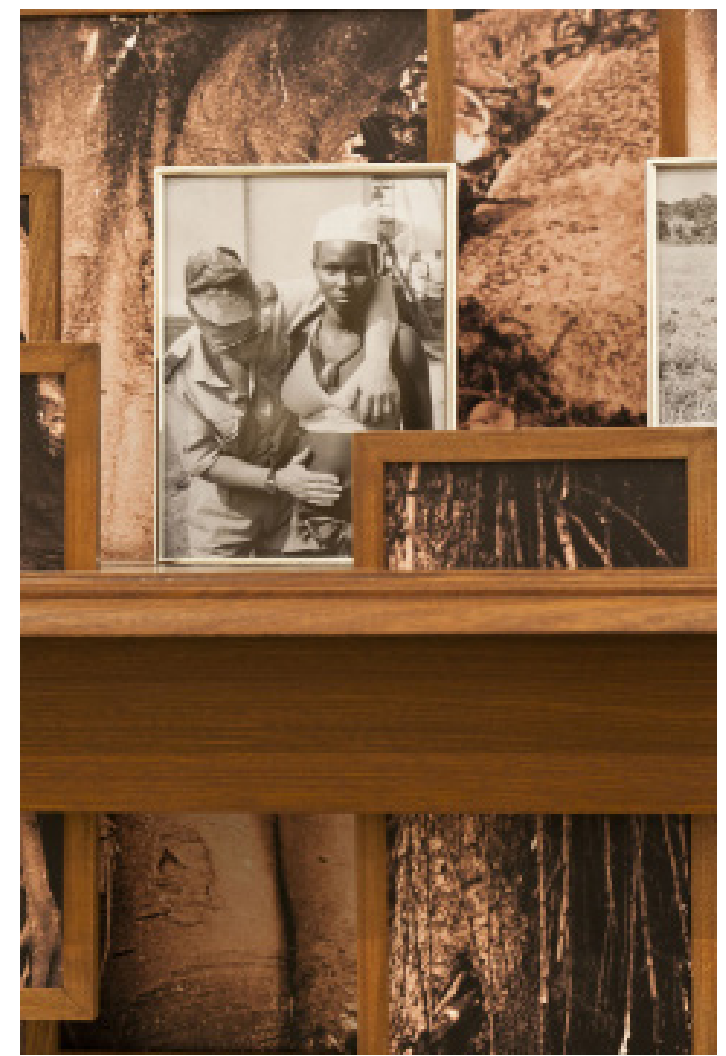

Figura 1: Exposição Botânica, detalhe do objeto escultórico, Vasco Araújo, 2014 Fonte: http://www.museuartecontemporanea.gov.pt/programs/view/5

\footnotetext{
2 O orientalismo, visto por Edward Said (1978), relaciona-se com o tratamento subalterno da cultura do "outro". É uma crítica do fenómeno do Orientalismo definido como "um conjunto de ideias circunscritas a valores, apresentados de modo generalizado, mentalidade, características do Oriente". Dessa forma, a cultura dominante se apodera da outra, a traduz a partir de uma gramática e imaginário próprios ao descrever a cultura do outro. Termina por estabelecer categorias e valores que se baseiam não na realidade, mas em necessidades políticas e sociais do Ocidente.

3 Exposição realizada no Museu Nacional de Arte Contemporânea do Chiado, Lisboa, Portugal, de 13 março a 18 maio de 2014.
} 
Para Stuart Hall, em Cultural Identity and Diaspora (1996), as práticas de representação implicam sempre posições a partir das quais escrevemos ou discursamos. A caracterização do "outro" contribuiu para a criação de categorias religiosas, raciais, sexuais e de gênero articuladas de formas variadas. Esse propósito superficial de identificação de diferenças desempenhou papel fundamental na cultura visual Ocidental. Ao criar o "outro" como um ser desqualificado, inferior em relação ao poder e saber ocidentais, a produção ocidental constituiu-se como forma de conhecimento hegemônico. Assim, utilizou-se e apropriou-se da existência e cultura do outro devido sua superioridade.

Esta ideia dialética de mundo, que contrapõe o colonizador e o colonizado, sendo a cultura do colonizador superior, além de produzir uma subalternização do "outro", imprimiu profundamente a ideia de inferioridade na mente do "outro", para que se considerasse incapaz de combater essa lógica. (Barradas, 2009). Foi a fotografia a responsável por construir, muitas vezes, a aceitação de um poder autoritário sobre o sujeito fotografado, poder que também controlava a produção e distribuição das imagens.

Essa assimetria de poderes levou à percepção de que as pessoas negras, sobretudo as mulheres, são sub-humanas ou animais. As imagens que mostram posições erotizadas da mulher, com nudez e aparente disponibilidade sexual ao branco colonizador, são fatores que a colocava não num mundo imoral, mas amoral, pois sua existência era alicerçada fora dos padrões estipulados pela moral colonizadora.

No contexto da relação colonial, diz Maria Baptista, "é preciso que o negro se cale, não tenha rosto, identidade ou memória" (2013, p. 284) e, "para que possa minimamente existir aos olhos do branco, tem de ser objeto de conquista e ordenação" (Baptista, 2013 , p. 285). A fotografia, neste contexto, foi utilizada como forma de apropriação dos corpos, das memórias e das identidades do Outro para representá-lo fora do processo histórico e do tempo, como não civilizado.

\section{A imagem da MUlher brasileira Pelo olHAR PORTUguês}

A invenção do cliché "brasileiro", ou seja, a criação de uma visualidade que pudesse traduzir o que, para determinado grupo de indivíduos, constituía o habitante original do "Novo Mundo", é um produto da história da imigração portuguesa para o Brasil. Além do termo "brasileiro" representar um bárbaro selvagem, também foi utilizado para representar o emigrante português ou "torna-viagem" ao regressar do Brasil. Segundo Jorge Fernandes Alves (2004), a consequente falta de oportunidades devido a economia marcada pela lavoura e a estagnação do crescimento econômico em Portugal, outorgava ao Brasil a possibilidade de um futuro melhor: "emigrar significava ir ao encontro de aspirações construídas no confronto com o meio e representações sociais nele dominantes, apoiadas no exemplo de figuras reais e próximas" (Alves, 2004, p. 195).

No Brasil, muitos fotógrafos se concentraram nas regiões portuárias, onde desembarcavam os escravos e autoridades. Entre os fotógrafos portugueses no Brasil, era o açoriano José Christiano Júnior que possuía a maior coleção de fotografias de escravos realizadas nos anos 1860 . Com uma coleção composta por 77 fotos, ele oferecia à 
clientela uma "variada coleção de costumes e typos de pretos, cousa muito própria para quem se retira da Europa" (Gorender, 1987, p. XXXI). Assim como o autor fotografava os escravos no exercício de suas funções (Figura 2), o que demonstra o interesse quase de classificação dos brasileiros existentes, há aquelas fotografias que se referem às mulheres negras como que expondo seu corpo disponível para o olhar do fotógrafo e do comprador. Eram mulheres apresentadas nuas, objetificadas, o que remete a como os escravos eram examinados detalhadamente nos mercados. Conforme aponta Freitas (2011, p. 65), as escravas eram alvos da luxúria dos senhores e para as quais eram dirigidas toda sorte de ações no âmbito sexual, uma vez que elas eram "tidas como meros objetos" nos quais "davam vazão a impulsos sexuais".

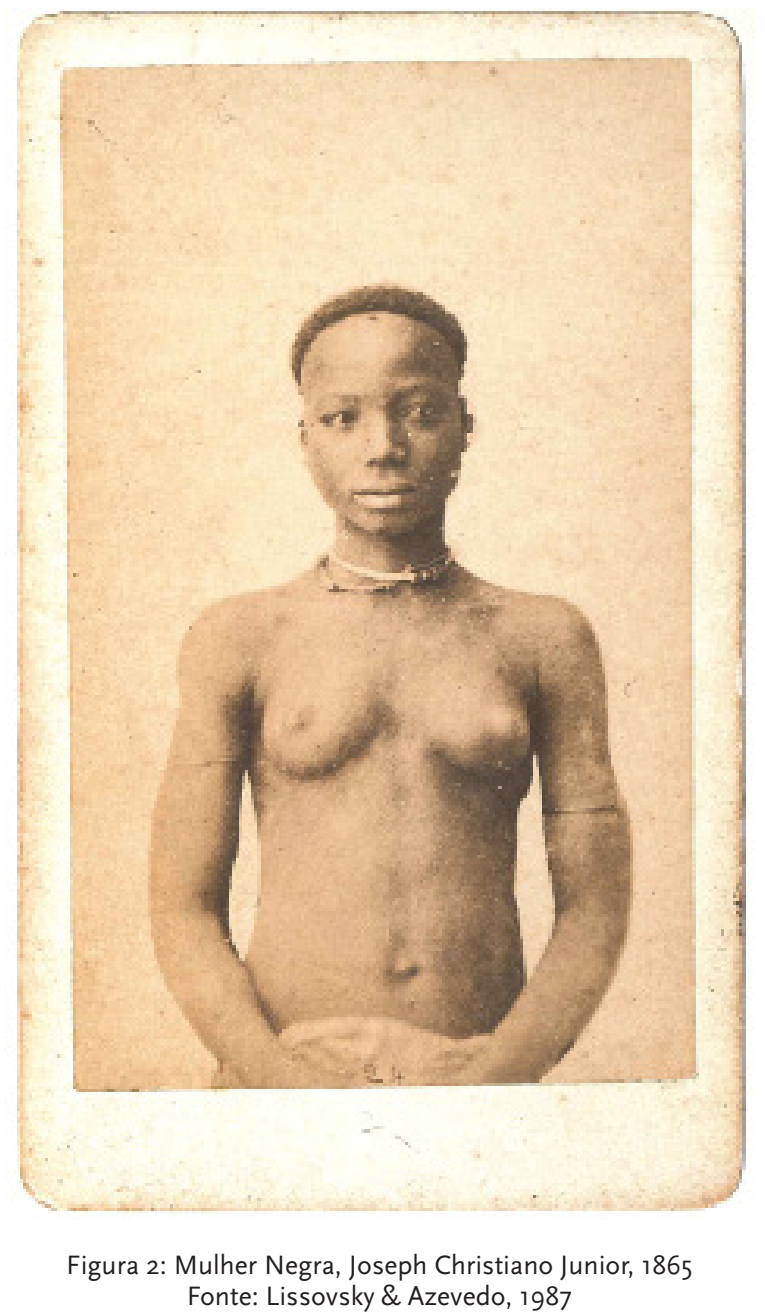

Os negros daquela época colonial compunham mais da metade da população do Rio de Janeiro, capital do império português àquela época, constituindo um "contingente tão expressivo que cronistas do período chegaram a comparar a paisagem carioca às cidades do litoral africano" (Lissovsky \& Azevedo, 1987, p. XXII). Christiano Júnior apresentava em suas cartes de visite "tipos de preto", ou seja, em suas fotografias os negros eram dispostos frontal e lateralmente para mostrar traços faciais, marcas de tribos e 
vestimentas, para realçar características próprias que definiam cada etnia e/ou profissão (técnica conhecida como bertillonage).

Essas fotografias, segundo Lissovsky e Azevedo (1987), eram direcionadas ao público que esteve isolado do mundo até 1808 , ano que em que houve a abertura dos portos brasileiros para o comércio internacional, o que acontecia concomitantemente com a instalação da Corte Portuguesa no Brasil. Trata-se de um conjunto de imagens que evoca tipos humanos e ofícios; basicamente são fotos de um estrangeiro e para estrangeiros. Importante ressaltar a ondulação de sentidos que alcança a carte de visite, a saber, se houvesse a imagem de um senhor de posses, poderia, então, se tornar o seu cartão de visita; no entanto, quando se apresenta o retrato do negro teria a função de cartão postal do Brasil. Enquanto o primeiro descreve uma pessoa digna e singular, o último descreve um personagem pitoresco e genérico (Cunha,1987).

Importante destacar que sempre houve uma associação de virilidade ao negro, fruto de uma hipersexualização herdada do período colonial. Esta prerrogativa atribui um olhar para o sexo para autenticar um encarceramento "na geografia da pele e da cor" (Pinho, 2004, p. 67). A hipersexualização do negro retira a natureza de homem para dar lugar a um animal, um fetiche.

De acordo com Luciana Pontes, que parte de um trabalho de campo realizado em Lisboa sobre as mulheres nos média, "a recente intensificação, no final dos anos 1990, da imigração brasileira complexificou os processos identitários mútuos, num quadro em que são criadas e/ou reforçadas velhas representações" (2004, p. 236). Nessas representações, a autora afirma que são verificados processos de essencialização e exotização da identidade nacional brasileira, além da sexualização das mulheres. Isto, como visto, acompanha a formação do Brasil e a utilização da fotografia colonial para representação do "outro" .

Por isso, é possível perceber que a sexualização das mulheres brasileiras nas imagens contemporâneas repete vários padrões estabelecidos nas fotografias coloniais. $O$ processo de sexualização da mulher imigrante brasileira surge em conexão tanto à condição de imigrante quanto a de ser oriunda de um país que tem um passado colonial e escravista. Há uma sobreposição de marcadores sociais de exclusão - colonialismo, o sexismo e o racismo - , que só reforça a posição colonial/subordinada e sexualizada.

No jornalismo português, a relação entre a imagem da brasileira e a prostituição foi propagada com mais intensidade a partir do caso conhecido como "Mães de Bragança", em 2003. Esse ocorrido, notícia inclusive da revista americana Times, foi resultado de um protesto das mulheres portuguesas contra a presença de mulheres brasileiras que estavam em Bragança para trabalhar em bordéis. As esposas decidiram se unir para expulsar as "destruidoras" de família. Esse caso contribui, ainda hoje, para uma associação generalista entre brasileiras e prostituição. Este processo resultou em fechamento de casas de alterne, prisões de algumas mulheres e repatriações das brasileiras ilegais. Para a imprensa portuguesa, era preciso fazer com que as mulheres de "sexualidade fácil" não invadissem o espaço particular reservado à família. 




\section{Detidas este ano 237 brasileiras}

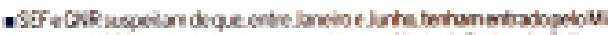



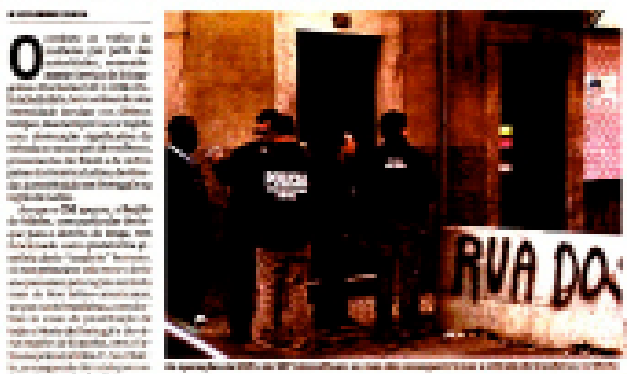

Figuras 3 e 4: capa da revista Time que apresenta Bragança como "Europe's New Red Light District" e um recorte de imprensa (de um jornal português) que mostra a detenção de mulheres brasileiras

Para Gomes (2012), a imprensa portuguesa tem sido importante para associação da imigrante brasileira com a prostituição. Um exemplo disto pode ser visto na polêmica capa da edição 565 da revista semanal portuguesa Focus (Os segredos da mulher brasileira, 2010) (Figura 5). Na capa, uma mulher com biquíni fio-dental serve de fundo para as manchetes: "Os segredos da mulher brasileira: Eles adoram-na, elas odeiam-na", "2.216 casamentos com portugueses só em 2009" e "Os dez mandamentos que usam para seduzir os homens". Na reportagem, as brasileiras são definidas, como oriundas de "Vera Cruz", nome que o Brasil recebia na época colonial, o que mostra uma abordagem explícita ao imaginário daquela época. Além disso, a mulher brasileira é representada de maneira fragmentada, com a exposição de parte de seu corpo como objeto sexual.

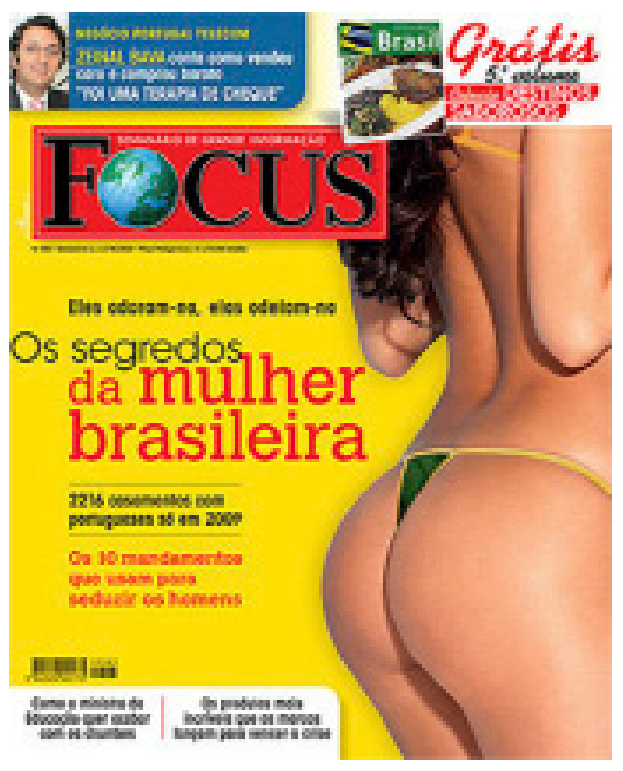

Figura 5: Capa da revista Focus

Fonte: Os segredos da mulher brasileira, 2010 
A brasileira sob o estigma do "corpo colonial", sempre será aquela com o corpo disponível, visto como objeto e entendido como uma constante "ameaça" para a família portuguesa. Esse corpo disponível, sexualizado, atinge todas as brasileiras, independente da função na sociedade ou do nível de escolaridade. A diferença de classe e escolaridade das brasileiras parece influenciar na vulnerabilidade ao estigma. Mulheres com baixa escolaridade e baixa renda ao exercer atividades domésticas ou de atendimento ao público são alvos de maior preconceito. A capacidade de reação organizada também é menor no grupo de maior vulnerabilidade, que termina por aceitar e até internalizar a ideia de cultura inferior (Gomes, 2012).

Atualmente, as empresas turísticas e a publicidade têm grande peso na propagação da imagem de um Brasil exótico ao apresentar mulatas com corpo nu como atrativo de pacotes turísticos. Isto tem mudado um pouco, segundo afirma Gomes (2012), pois o órgão responsável pelo turismo brasileiro e a imprensa portuguesa estão, atualmente, desconstruindo o imaginário da mulher mulata e erotizada, para construir outros imaginários do Brasil com a apresentação de elementos da cultura em detrimento de corpos expostos. Isso, deve-se, em parte, pela pressão exercida pelos movimentos sociais brasileiros no Brasil e em Portugal.

\section{A IMAGEM DA MULHER BRASILEIRA NA FOTOGRAFIA CONTEMPORÂNEA PORTUGUESA: ANDRÉ Cepeda e Miguel Valle de Figueiredo}

A existência e a ação do indivíduo em sua realidade tal qual esta se apresenta é condicionada pela diferença de modos de olhar o mundo, de interpretá-lo e de possuí-lo. É na dupla distância, entre a imagem e aquilo que ela representa e a imagem e o ser que a olha, que se encontram, concomitantemente, o sentido e a perda: a construção do sentido do que é representado por meio de um discurso articulado pela cultura e a perda do objeto/sujeito em sua existência causada pela opacidade de sua representação. Deste modo, a construção de imagens é compreendida como processo de (re)conhecimento pelos quais se desenvolvem as condições de pertença e estranhamento do ser e sua relação com a realidade.

Enquanto as imagens veiculadas diariamente pelos aparatos técnicos informacionais e comunicacionais provocam a "massmidialização embrutecedora" (Guattari, 1992, p. 16) de um grande número de indivíduos; uma parte significativa das imagens efetuadas no âmbito da arte contemporânea e os princípios de criação que seguem, visam promover experiências que possibilitem a geração de paradoxos em relação à atual realidade estetizada. A experimentação desse paradoxo pode apontar para a construção de uma criticidade em relação aos processos de agenciamento estabelecidos pelo sistema cultural globalizante vigente:

essa catálise poético-existencial, que encontraremos em operação no seio de discursividades escriturais, vocais, musicais ou plásticas, engaja quase sincronicamente a recristalização enunciativa do criador, do intérprete e do apreciador da obra de arte. Sua eficácia reside essencialmente em sua 
capacidade de promover rupturas ativas, processuais, no interior de tecidos significacionais e denotativos semioticamente estruturados. (Guattari, 1992, p. 31)

A construção poética do objeto artístico, segundo Guattari, possui a potência de desconstrução dos enunciados generalizantes, uma vez que oferece ao espectador uma distorção do sistema de significados consolidados na/pela atual cultura globalizada, ampliando as possibilidades sensíveis dos indivíduos. Tal objeto, mesmo sendo trivial, exibe a alteridade, uma vez que a estética artística contemporânea constitui-se, no entendimento de Ferry (2003, p. 31), como uma extensão do próprio artista, "uma espécie de cartão de visita particularmente elaborado" pelo qual se apresentam "como outros tantos "pequenos mundos perceptivos" que não representam já o mundo, mas o estado de forças vitais de seu criador" (Ferry, 2003, p. 32). Assim, a imagem, sendo familiar, é contígua à estranheza, por revelar não mais um discurso do que seja estranho, criado coletivamente por seu contexto, como outrora feito, mas que oferece a criação de intersubjetividade pela possibilidade de diálogo com o mundo criado peculiarmente pelo artista.

Considerando tais perspectivas, busca-se aqui analisar a visualidade criada sobre a "brasileira" nas imagens fotográficas produzidas por André Cepeda e Miguel Valle de Figueiredo. A escolha desses dois fotógrafos visa, ainda, uma aproximação sobre o modo como ainda é percebida a mulher brasileira na fotografia de portugueses, devido às relações de colônia que manteve com o Brasil. Neste artigo, interessa refletir sobre as referências encontradas nas imagens atribuídas como identidade da mulher brasileira para verificar como isso influencia o reconhecimento da brasileira na contemporaneidade, no caso expresso, por meio dos olhares desses fotógrafos.

Tem-se em conta que, segundo as reflexões pós-modernas da fotografia, cada imagem se referencia a outras, construindo paralelos, diacronias, sincronias e dialéticas, construindo uma teia de significância cujo resultado está além da intencionalidade do autor. Nessa perspectiva, "as fotografias foram vistas como sinais que adquiriram seu valor a partir de sua inserção no bojo de um sistema mais amplo de codificações sociais e culturais" (Cotton, 2013, p. 191). Desse modo, é assim que aqui se entende os trabaIhos apresentados: como parte de uma grande tessitura histórica, social e política da qual emergem diferentes relações, incluindo as coloniais.

\section{André Cepeda, Rua Stan Getz (2014)}

André Cepeda (nascido em Coimbra, 1976) vive e trabalha em Lisboa. Desde 2005 tem trabalhado muito com a paisagem contemporânea portuguesa, particularmente a do Porto. O fotógrafo utiliza a câmara de grande formato $(4 \mathrm{~m} \times 5 \mathrm{~m})$ porque, além de ser, em sua opinião, mais precisa e permitir uma técnica acurada, ela requer um processo lento de trabalho, determinando assim o seu método: uma longa e atenta observação das coisas que o permite se conectar e/ou se relacionar com o objeto ou paisagem que deseja fotografar. 
O fotógrafo afirma, em seu sítio na internet ${ }^{4}$, que está interessado em construir novas formas de olhar a realidade e o espaço que são apresentados a ele. Essencialmente, para ele há uma procura em seus trabalhos por espaços e momentos que têm sido rejeitados, sugerindo uma certa suspensão. O seu interesse, portanto, se baseia no sentimento que o torna obrigado a criar uma imagem e relatar o seu espaço, tentando esquecer sua história e contexto original de recepção. Dessa forma, ele tem como único foco a luz, espaço e tempo. Assim, ele se sente mais livre para criar novos contextos para as imagens, como se esse tratamento quase escultural retomasse uma dignidade que foi renegada ao objeto/paisagem. Para o fotógrafo, essas imagens se tornam um momento de reflexão mais ampla sobre a maneira como construímos nossa identidade cultural, social e política.

O trabalho do artista na cidade de São Paulo, no Brasil, logrou três meses de olhares e percursos que o levaram a uma cidade peculiar 5 . Trata-se de um trabalho mais escultural, que relata o espaço selecionado pelo fotógrafo. As imagens realizadas misturam a experiência de flânerie do fotógrafo que exibe ruas, transeuntes, paisagens, reflexos do espaço da cidade na lente do fotógrafo a registar seu olhar sobre o caminho construído. O resultado dessa experiência resultou no livro Rua Stan Getz (2014), que também apresenta retratos, na sua maioria compostos por mulheres nuas (Figuras 6, 7, 8 , 9). São mulheres de corpos peculiares, construindo a ideia da diversidade étnica no Brasil ao mostrar "a diversidade de tom de peles"6. O autor afirma que utilizou modelos-vivos que posavam na Faculdade de Artes de São Paulo da Fundação Armando Álvares Penteado (FAAP) em suas fotos.

Neste ensaio, o fotógrafo utiliza um número maior de nus femininos em comparação aos outros já realizados. Diante das fotos do projeto brasileiro, torna-se impossível não encontrar referências etnográficas coloniais e até da pintura clássica. $O$ autor afirmou em entrevista que as mulheres são apresentadas sem vestimentas para seguir o modelo da História da Arte.

Como referência à pintura clássica, toma-se como exemplo a fotografia em que uma mulher negra nua (Figura 8) está reclinada sobre uma cama (o nu reclinado é bastante tradicional na pintura, como bem se sabe). Nela, pode-se seguir a tentação de repetir a fala de que a mulher ao encenar a pose clássica da pintura exibe-se como objeto erótico. O seu olhar, ao mesmo tempo que encara o fotógrafo encara também o espectador, sendo objetificada duas vezes (Ewing, 1996). Mas, a mulher em questão, por ser modelo-vivo para pintores, recorre deliberadamente à performance no retrato para representar uma pose clássica e muitas vezes utilizada com atribuições simbólicas diversas ${ }^{7}$.

\footnotetext{
4 Disponível na secção "About" em http://www.andrecepeda.com/

${ }^{5}$ Esta informação é baseada no texto "São Paulo em corte" de Agnaldo Farias, publicado no site de André Cepeda, disponível em http://www.andrecepeda.com/projects/ sao-paulo-em-corte/

${ }^{6} \mathrm{~A}$ entrevista foi realizada no âmbito do debate estabelecido com o artista na "Escola de Verão de Fotografia: arquivo, teoria e história", com organização de Filipa Vicente Lowndes, em 22 de setembro de 2017.

7 Manet quando pintou Olympia (1863) tinha a Vênus de Urbino de Titian como inspiração. No entanto, em vez de pintar na tradição artística aceita, com temas bíblicos ou mitológicos, Manet escolheu pintar uma mulher real, talvez uma prostituta
} 


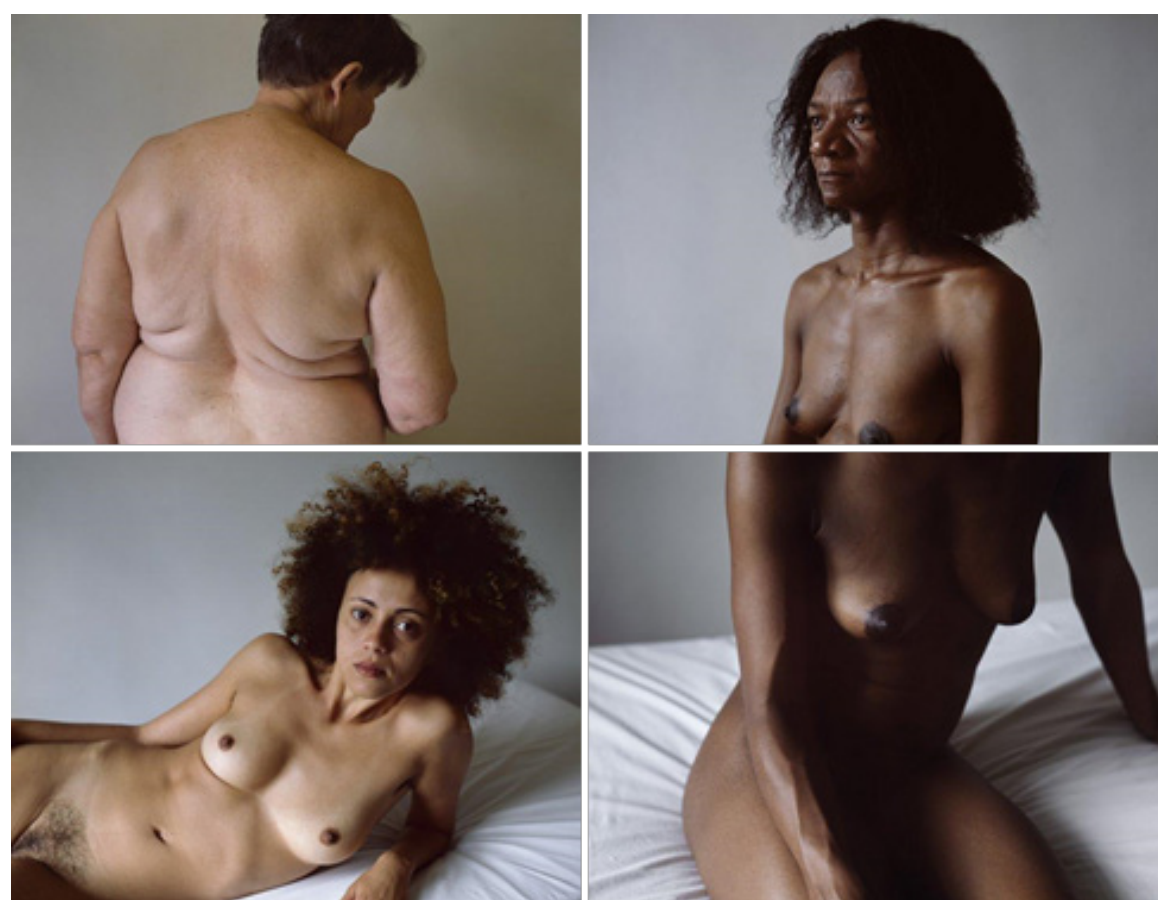

Figuras 6, 7, 8 e 9: André Cepeda, Rua Stan Getz, 2014 Fonte: http://www.andrecepeda.com/projects/rua-stan-getz/

Neste contexto, "para se reconhecer em um retrato (e no espelho), imita-se a imagem que imagina-se que o outro vê" (Phelan,1993, p. 36). A pose é uma atitude teatral que oferece uma imagem já definida "a partir de um conjunto de normas, das quais faz parte a percepção do próprio eu social" (Fabris, 2004, pp. 35-36). O retrato por ser tomado por uma representação do que o outro vê termina por representar o "olhar masculino" da mulher interpretado pela própria mulher. Como a Olympia (1863) de Manet, o retrato passa a ser constituído por uma dobra de significados que vacilam entre o que se é e o que se deve parecer. Ao gerar outra imagem de si ou para si, o retrato torna-se uma espécie de simulacro. Neste jogo, a autoimagem da mulher reflete o ponto de vista masculino, lugar que determina como deve ser a pose e, por isso, a sua própria representação.

No que se refere à recordação de estilo etnográfico em seu trabalho, pode-se destacar a fotografia que mostra uma mulher negra que, nua, é posta de modo a mostrar seu perfil sem olhar para a câmara (Figura 7). Cepeda assume, tal como os fotógrafos coloniais, representar aquela grande quantidade de gradações de pele neste pequeno inventário das mulheres que encontrou no Brasil. De acordo com a página eletrônica do autor, ele procura esquecer a história e o contexto original de recepção do objeto da fotografia. Disto pode-se constatar que o autor ao esquecer toda a história colonial Brasil-Portugal, como também a da representação da mulher, termina por representar a da mulher brasileira de forma banal e isenta de preocupações sociais e políticas que podem ser associadas ao corpo explorado.

no papel de Vênus. Olympia reclina na mesma posição que a Vênus de Ticiano, ela lança ao espectador um poderoso olhar desconcertante. Deste modo, Manet negou a estrita classificação da sexualidade feminina representada pelos pintores tradicionais. 
Impõe-se, ainda ao juízo do espectador, uma única figura masculina do livro (Figura 10), que está totalmente vestida. A julgar pelo pensamento de Cotton (2013, p. 191), a imagem adquire seu valor "a partir de sua inserção no bojo de um sistema mais amplo de codificações sociais e culturais". Há um estranhamento causado ao espectador pelo contraste do nu feminino e do homem sério e vestido.

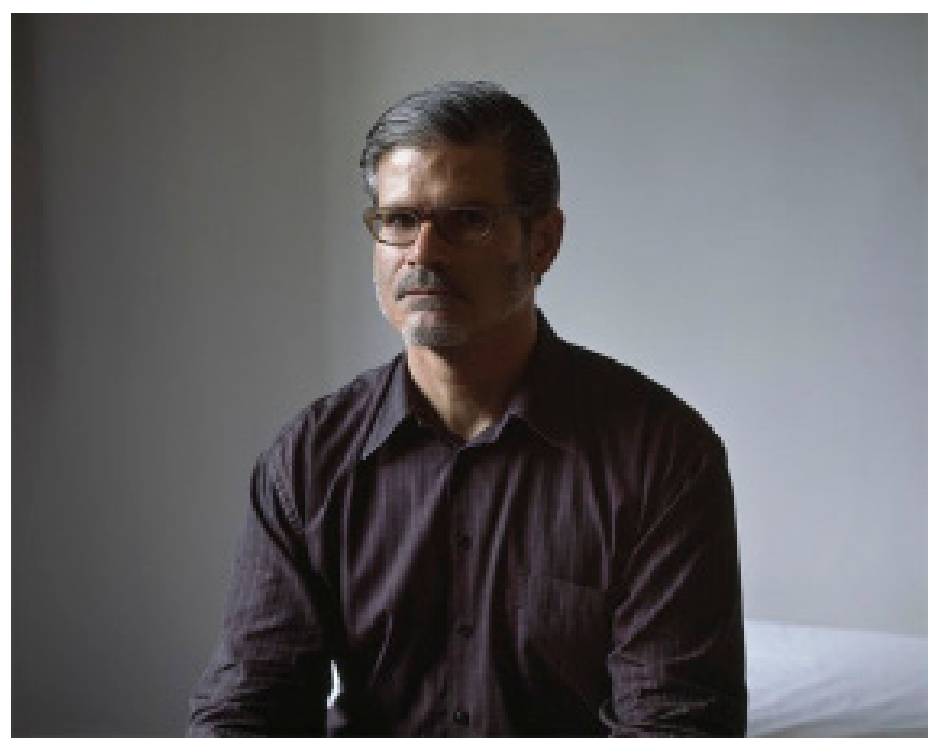

Figura 10: Rua Stan Getz, André Cepeda, 2014 Fonte: http://www.andrecepeda.com/projects/rua-stan-getz/

No livro Rua Stan Getz (2014), não há textos explicativos que demonstrem qualquer inclinação patriarcalista em suas imagens. No entanto, fazendo um contraponto com o discurso do fotógrafo, - que repete a representação da mulher na pintura, expõe um olhar sexista e despreocupado com o contexto cultural e histórico do fotografado o ensaio exibe imagens da mulher brasileira que fortalecem o estereótipo colonial combatido pelo feminismo e pós-colonialismo.

\section{Miguel Valle de Figueiredo, Brasil (2007-2008)}

Miguel Valle de Figueiredo nasceu em Santa Comba Dão, no distrito de Viseu, Portugal. É fotografo profissional desde 1986, com trabalhos nas áreas industrial, de engenharia/arquitetura e editorial. Em 1994, foi cofundador da revista "Volta ao Mundo", publicação destinada a expor possíveis rumos de viagens, realizando reportagens em mais de 50 países. Miguel já foi ao Brasil cerca de 30 vezes, sendo duas dessas vezes de férias. O autor diz conhecer o Brasil mais que muitos brasileiros. Em 1997, ganhou o prêmio Fuji-European Press Award na categoria de Grande Reportagem, com uma das fotos realizadas no interior do estado do Ceará, Brasil.

Em conversa com o fotógrafo ${ }^{8}$, ele destaca que suas incursões no Brasil são resultado de trabalhos para publicações turísticas e que por esse motivo muitas de suas

\footnotetext{
${ }^{8}$ Entrevista concedida no dia 10 de agosto de 2016, na Fundação Calouste Gulbenkian, a Lorena Travassos.
} 
imagens não fogem da iconografia atribuída ao país tropical de belas paisagens e terra da "garota de Ipanema". Porém, em sua fala, Miguel Valle de Figueiredo expõe que esse mito sobre a mulher brasileira, criado pelos próprios brasileiros, não existe, pois, na extensão do país cada brasileira é uma - com suas peculiaridades no andar, no falar, no agir.

No entanto, não são muitas as fotografias de mulher em seu trabalho, surgindo a paisagem "exótica" com predominância em seu portfólio acessível na sua página Flickr. O autor, porém, fotografou peculiaridades de um Brasil continental e desigual. Parece que ao nos trazer a especificidade de pequenos vilarejos do nordeste e de seus habitantes acentua essa desigualdade e escancara um país não mais tão generoso em recursos como carta de Caminha anunciou no momento da conquista portuguesa. A conquista da natureza paradisíaca gerou, de fato, vários "Brasis". Este Brasil, exibido nas fotos premiadas do fotógrafo, reforça a ideia do país mestiço e apresenta os paradoxos e contrastes nos modos de viver dos indivíduos e sociedades que compõem a nação.

Por ser praticamente de cariz publicitário, a mulher surge junto com a paisagem como representação exótica do local. Há um beleza exótica e sensual que é suposta pertencer às mulheres brasileiras, herança da visão colonial imposta aos negros e aos índios que eram vistos como poligâmicos, incestuosos (Vanifas, 1997). Coube ao fotógrafo, em seu trabalho comercial, a tarefa de reproduzir "A garota de Ipanema", música de Tom Jobim que foi responsável por idealizar a mulher do Rio de Janeiro (Figura 11). Como não pode faltar na representação do cliché do brasileiro na fotografia de viagem, a natureza se mostra como habitat que abriga a mulher, seminua, selvagem, que como uma medusa parece hipnotizar os homens que encontra (Figura 12).


Figuras 11 e 12: Miguel Valle de Figueiredo, A Girl from Ipanema (2008); Mermaid (2007) Fonte: https://www.flickr.com/photos/miguelvf/albums/72157603760063735 
Ao dizer que não consegue "estabelecer aquilo que é o brasileiro, enquanto objeto de retrato", o fotógrafo diz que tal afirmação "não é a mesma coisa de dizer que" não consiga "fotografar os diversos brasileiros, como 'o' brasileiro". Faz referência, ainda aos vários tipos que há no Brasil, pois não há como traduzir "duzentos milhões de pessoas com tanta variedade" e conclui: "A lógica rácica no Brasil é muito difícil de mapear fotograficamente."

O registo de Miguel Valle cujas proposições fotográficas relacionam-se ao olhar publicitário, busca provocar o consumo, propondo ao consumidor uma experiência no mundo estetitizado do "capitalismo artista" 9 (Lipovetsky \& Serroy, 2015, p. 62). Por mais que se possa perceber que há uma diversidade de identidades no Brasil, esconde-se aí também a situação de mercadoria que a cultura e identidades do sujeito surgem para fortalecer estereótipos, como é o caso da "mulher brasileira" vendida como atrativo em pacotes turísticos por todo o mundo.

A sua escolha não se dá objetivamente por uma identidade, por definir quem seria a "brasileira", mas apresentar uma identidade estereotipada da brasileira, uma mulher de forma acessível e conectada aos mitos que fazem parte da história do Brasil.

\section{CONSIDERAÇÕES FINAIS}

Segundo Marilena Chauí (1995, p. 34) o olhar abriga ao mesmo tempo uma atividade, uma vez que o gesto de olhar nasce e depende da experiência de cada indivíduo, mas exerce-se também em uma passividade ancorada nas construções discursivas que engendram o mundo. Pode-se atribuir esta passividade ao consumo das novas formas imagéticas daquilo que podemos chamar de uma estética colonial contemporânea, em cujos discursos se articulam e se propagam as imagens construídas e divulgadas pelas atuais médias de informação e que tanto elegem as padronizações impostas pelos sistemas generalizantes, como também podem implicar e formalizar o entendimento sobre determinada cultura e sobre os sujeitos dessa cultura.

A construção da imagem da mulher revelou discursos apoiados em percepções e experiências, mas também nas atribuições de valores generalizantes, que uniu valores de raça e inferioridade às mulheres. Por isso, falar da mulher brasileira contemporânea é também falar das questões de raça e da visão colonial que sobrepõem a questão de gênero.

Com base nesta apreciação, afirma-se que André Cepeda e Miguel Valle de Figueiredo revelaram discursos generalizantes do país. Figueiredo, que esteve mais de 30 vezes ao Brasil, retratou de forma totalmente comercial as terras e gentes brasileiras. $\mathrm{O}$ seu interesse está alicerçado em um caráter puramente comercial ao representar imagens pitorescas acompanhadas do corpo feminino. Em suas imagens, ele expõe a muIher como parte da natureza, como animal exótico, além de, inconscientemente ou não, favorecer também um comércio sexual por meio das imagens.

\footnotetext{
9 O capitalismo artista não só desenvolveu uma oferta proliferante de produtos estéticos, como criou um consumidor faminto de novidades, de animações, de espetáculos, de evasões turísticas, de experiências emocionais, de fruições sensíveis: em outras palavras, um consumidor estético ou, mais exatamente, transestético (Lipovetsky \& Serroy, 2015, p. 62).
} 
Por seu lado, Cepeda remonta uma espécie de catalogação de tipos femininos. A escolha de nus femininos, segundo o autor, remete à questão da representação da muIher da arte clássica e da sua recusa em fotografar pessoas do mesmo sexo. Se a estética artística é uma extensão do próprio artista (Ferry, 2003), o trabalho ou "cartão de visita" do fotógrafo revela a sua reflexão geral sobre o Brasil. Quando utilizou-se do artifício da pose e modelos, o autor representou a brasileira sem preocupação com o contexto histórico e cultural que interfere na compreensão de uma mulher brasileira atual. Essa forma de representação, sem julgo ou reflexão, termina por nos fazer acreditar que o mundo construído pelo autor em seu trabalho repete antigas concepções ao representar a mulher "brasileira". Afinal, se o corpo é político, ao ser neutro em situações de injustiça, corre-se o risco de representar o lado opressor.

Conclui-se que as peculiaridades do atual entendimento sobre a imagem do corpo da mulher brasileira, especificamente aquele conformado pelo olhar português nas imagens analisadas, mostra-se revestido de novos processos colonizadores, em que à imagem da brasileira associa-se tanto a sensualidade como a disposição sexual, impregnado pela compreensão de um corpo colonial que ainda persiste no imaginário contemporâneo e surge como nódoa na imagem da brasileira.

\section{REFERÊNCIAS BIBLIOGRÁFICAS}

Alves, J. F (2004). O "brasileiro" oitocentista - representações de um tipo social. In B. Vieira (Ed.), Grupos sociais e estratificação social em Portugal no Século XIX (pp. 193-199). Lisboa: ISCTE.

Baptista, M. M. (2013). A Identidade cultural Portuguesa: do colonialismo ao pós-colonialismo: memórias sociais, imagens e representações identitárias. Comunicação e Sociedade, 24, 270-287.

Barradas, C. (2009). Poder ver, poder saber. A fotografia nos meandros do colonialismo e pós-colonialismo. Revista Arquivos da memória: Antropologia, Arte e Imagem, 5-6, 59-79.

Barthes, R. (1984). A câmara clara. Rio de Janeiro: Nova Fronteira.

Berger, J. (1972). Ways of seeing. Londres: Penguin Books.

Butler, J. (1997). Problemas de gênero: feminismo e subversão da identidade. Porto Alegre: Tomo Editorial/ Palmarinca.

Cepeda, A. (2014). Rua Stan Getz. Lisboa: Pierre Von Kleist Editions.

Chauí, M. (1995). Janela da alma, espelho do mundo. In A. Novaes (Ed.), O olhar (pp. 31-63). São Paulo: Cia das Letras.

Cotton, C. (2013). A fotografia como arte contemporânea. São Paulo: Martins Fontes.

Cunha, M. C. (1987). Olhar Escravo, Ser Olhado. In M. Lissovsky \& P. Azevedo (Eds.), Escravos brasileiros do século XIX na fotografia de Christiano Jr (pp. xxiii- xxx). São Paulo: Editora Ex Libris.

Edwards, E. (2008). Representação da Mudança: A Construção do Etnográfico na Fotografia do século XIX. Revista Comunicação e Linguagens, 39, 97-118.

Ewing, W. (1996). The body: photoworks of the human body. Londres: Thames \& Hudson. 
Fabris, A. (2004). Identidades visuais: uma leitura do retrato fotográfico. Minas Gerais: Editora UFMG.

Ferry, L. (2003). Homo Aestheticus - a invenção do gosto na era democrática. Coimbra: Almedina.

Freitas, M., (2011). O cotidiano afetivo-sexual no Brasil colônia e suas consequências psicológicas e culturais nos dias de hoje. Ponta de Lança: Revista Eletrônica de História, Memória Q Cultura, 5(9), 53-58. Retirado de http://www.seer.ufs.br/index.php/pontadelanca/article/view/1577/2710

Freud, S. (1974). Fetichismo. In Obras Psicológicas Completas de Sigmund Freud. Edição standard brasileira Vol. XXI (pp. 173-185). Rio de Janeiro: Imago.

Guattari, F. (1992). Caosmose. Um novo paradigma estético. São Paulo: Ed. 34.

Gomes, M. S. (2012). A imagem do Brasil no exterior e o turismo: a operacionalização do Plano Aquarela em Portugal. Rosa dos Ventos, 4(4), 506-521. Retirado de http://www.ucs.br/etc/revistas/index.php/ rosadosventos/article/view/1494

Gorender, J. (1987). A face escrava da Corte Imperial Brasileira. In M. Lissovsky \& P. C. Azevedo (Eds.), Escravos brasileiros do século XIX na fotografia de Christiano Jr (pp. xxxi-xxxvi). São Paulo: Editora Ex Libris.

Hall, S. (1996). The work of representation. In S. Hall (Ed.), Representation. Cultural representation and cultural signifying practices (pp. 13-74). Londres, Thousand Oaks \& New Delhi: Sage.

Higonnet, A. (1992). Criar, Criações: séculos XIX e XX. In G. Duby \& M. Perrot (Eds.), Imagens da Mulher (pp.140-173). Porto: Edições Afrontamento.

Hirschfeld, M. (1982). Fetichismo: fonte de amor. In Enciclopédia da educação sexual [Vol. 2], p. 199. São Paulo: Iracema.

Leite, M. (2011). As fotografias cartes de visite e a construção de individualidades. Interin: Revista do programa de Pós- Graduação em Comunicação e Linguagens, 11(1), 1-16. Retirado de http://interin.utp.br/index.php/ vol11/article/viewFile/42/34.

Le Goff, J. (2003). Documento/Monumento. In História e Memória (pp. 525-539). Campinas, São Paulo: Unicamp.

Lipovetsky G. e Serroy, J. (2015). A estetização do mundo: viver na era do capitalismo artista. São Paulo: Companhia das Letras.

Lissovsky, M. \& Azevedo, P. (1987). O fotógrafo Cristiano Jr. In M. Lissovsky \& P. Azevedo (Eds.), Escravos brasileiros do século XIX na fotografia de Christiano Jr. (pp. ix-xv). São Paulo: Editora Ex Libris.

Mulvey, L. (1975). Visual Pleasure and Narrative Cinema. Screen, 16(3), o6-27.

Mulvey, L. (1989). Afterthoughts on 'Visual Pleasure and Narrative Cinema' inspired by King Vidor's Duel in the Sun (1946). In Visual and Other Pleasures (pp. 29-38). Londres: The Macmillan Press Ltd.

Mulvey, L. (1996). Fetishism and Curiosity. Londres: British Film Institute.

Metz, C. (1985). Fotografía y fetiche. Revista Octobre, 34, 123-133.

Naranjo, J. (2006). Fotografía, antropología y colonialismo (1845-2006). Barcelona: Colección FotoGGrafia.

Os segredos da mulher brasileira (2010, agosto). Focus, 555.

Phelan, P. (1993). Unmarked: The Politics of Performance. Londres \& Nova lorque: Routledge. 
Pinho, O. (2004). Qual é a identidade do homem negro? Revista Democracia Viva, 22, 64-69.

Pontes, L. (2004). Mulheres brasileiras na mídia portuguesa. Cadernos Pagu, 23, 229-256. Retirado de http://www.scielo.br/pdf/cpa/n23/n23ao8.pdf

Roberts, A. (1988). Photographs and African history: Review Article. Journal of African History, 29, 301-311. Retirado de http://www.jstor.org/stable/182386

Said, E. (1978). Orientalismo: O oriente como invenção do Ocidente. São Paulo: Companhia das letras.

Solomon-Godeau, A. (1991). Photography at the dock : essays on photographic history, institutions, and practices. Minneapolis: University of Minnesota Press.

Vanifas, R. (1997). Moralidades brasílicas: deleites sexuais e linguagem erótica na sociedade escravista. In C. F. Cardoso \& R. Vainfas (Eds.), História da vida privada no Brasil (pp. 221-274). São Paulo: Companhia da Letras.

Vicente, F. (Ed.) (2014). O império da visão: fotografia no contexto colonial português (186o-1960). Lisboa: Edições 70.

\section{WEBGRAFIA}

André Cepeda, About André Cepeda. Retirado de http://www.andrecepeda.com/

André Cepeda, Rua Stan Getz, Retirado de http://www.andrecepeda.com/projects/rua-stan-getz/

André Cepeda, São Paulo em corte, Agnaldo Farias, Retirado de http://www.andrecepeda.com/projects/ sao-paulo-em-corte/

Miguel Valle de Figueiredo, Página de Flickr, Álbum Ain't life a beach?, Retirado de https://www.flickr.com/ photos/miguelvf/albums/72157603760063735

Museu Nacional de Arte Contemporânea do Chiado, Programação, Botânica de Vasco Araújo, Retirado de http://www.museuartecontemporanea.gov.pt/programs/view/5

Photo Clec Project (Photographs, Colonial Legacy and Museums in Contemporary European Culture), Retirado de http://photoclec.dmu.ac.uk/

Vasco Araújo, Botanica. Retirado de http://vascoaraujo.org/Botanica

\section{Nota BiográficA}

Lorena Travassos é mestre em Comunicação (UFPB - Brasil), doutoranda em Ciências da Comunicação na Universidade Nova de Lisboa (FCSH-UNL), investigadora do Center for Research in Communication, Information and Digital Culture - Polo FCSH/ NOVA (CIC.Digital), bolsista do Programa de Doutorado Pleno da CAPES - Brasil. E-mail: lorenakrs@gmail.com

Rua Diogo do Couto, 27, 1D, Lisboa, 1100-195, Portugal 
* Submetido: 24-07-2017

* Aceite: 09-11-2017 